\title{
Appropriateness of Adrenocorticotropic Hormone Stimulation Test for Critically III Patients
}

\author{
Osric Sin, Glen Brown, and Greg Grant
}

\begin{abstract}
Background: In earlier work, it was shown that patients with septic shock who also have adrenal insufficiency experience a benefit in terms of lower mortality rates with hydrocortisone supplementation. As such, the adrenocorticotropic hormone (ACTH) stimulation test has been used frequently to identify these patients. However, recent evidence has suggested that the identification and treatment of adrenal insufficiency in patients with septic shock does not reduce mortality. These results call into question the utility of the ACTH stimulation test in this patient population.
\end{abstract}

Objectives: To determine the indications for ordering the ACTH stimulation test for critically ill patients at a tertiary care hospital and to classify the indications as either appropriate (e.g., primary adrenal insufficiency or medication-induced suppression of the hypothalamuspituitary-adrenal axis) or inappropriate (e.g., patients with septic shock, prior etomidate exposure, or absence of steroid use).

Methods: A retrospective analysis of health care records was conducted for all patients who had been admitted to the intensive care unit and who had undergone an ACTH stimulation test during 2007. For each patient, the indication for the test was identified and classified as appropriate or inappropriate.

Results: A total of 35 ACTH stimulation tests were performed during the study period, of which $8(23 \%)$ were classified as having an appropriate indication and $27(77 \%)$ as having an inappropriate indication. Of the tests with an inappropriate indication, 15 (56\%) were ordered for patients with septic shock. However, the number of ACTH tests ordered for this indication declined as the year progressed.

Conclusions: The ACTH stimulation test was often used inappropriately for patients with septic shock. Over time, there appeared to be a trend away from use of this test in this patient population, perhaps reflecting increasing awareness of the lack of benefit.

Key words: adrenocorticotropic hormone stimulation test, septic shock, adrenal insufficiency

\section{Can J Hosp Pharm 2010;63(1):9-12}

\section{RÉSUMÉ}

Contexte : Dans des travaux antérieurs, on a observé un taux de mortalité moindre lorsque les patients qui souffraient à la fois d'un choc septique et d'insuffisance surrénalienne recevaient un supplément d'hydrocortisone. Ainsi, on a eu souvent recours à une épreuve de stimulation par l'adrénocorticotrophine (ACTH) pour dépister de tels patients. Cependant, des données récentes suggèrent que le dépistage et le traitement de l'insuffisance surrénalienne chez les patients en choc septique ne réduisent pas la mortalité. Ces résultats remettent en question l'utilité de l'épreuve de stimulation par l'ACTH dans cette population de patients.

Objectifs : Déterminer les indications commandant une épreuve de stimulation par l'ACTH chez les patients gravement malades d'un hôpital de soins tertiaires et classer les indications comme étant soit appropriées (p. ex., insuffisance surrénalienne primaire ou suppression de l'axe hypothalamo-hypophyso-surrénalien causée par les médicaments), soit inappropriées (p. ex., patients en choc septique, exposition antérieure à l'étomidate ou non-recours à un corticostéroïde).

Méthodes : On a effectué une analyse rétrospective des dossiers médicaux de tous les patients admis à l'unité de soins intensifs de l'hôpital et qui avaient subi une épreuve de stimulation par l'ACTH en 2007. On a recensé pour chaque patient l'indication commandant l'épreuve et classé chaque indication comme étant appropriée ou inappropriée.

Résultats : Un total de 35 épreuves de stimulation par l'ACTH ont été réalisées, dont 8 (23\%) ont été classées comme étant appropriées et 27 (77\%) comme étant inappropriées. Des épreuves dont l'indication a été classée comme étant inappropriée, 15 (56\%) ont été commandées pour des patients ayant un choc septique. En revanche, le nombre d'épreuves par l'ACTH commandées pour cette indication a diminué au fil de l'année.

Conclusions : L'épreuve de stimulation par l'ACTH a été souvent indiquée de façon inappropriée chez les patients en choc septique. Au fil du temps, on a observé une tendance à l'abandon de cette épreuve dans cette population de patients, traduisant peut-être une meilleure sensibilisation à l'absence de mérite.

Mots clés : épreuve de stimulation à l'adrénocorticotrophine synthétique, choc septique, insuffisance surrénalienne

[Traduction par l'éditeur] 


\section{INTRODUCTION}

The adrenal gland is responsible for the production and I secretion of many hormones in the body, including glucocorticoids, specifically cortisol. ${ }^{1}$ During sepsis or septic shock, patients may not produce enough cortisol relative to the demand created by the stress imposed on the body; this may cause a transient state of relative adrenal insufficiency contributing to hemodynamic instability. ${ }^{2,3}$ The overall incidence of adrenal insufficiency among critically ill patients has been reported as about 30\%; among patients with septic shock, the incidence can be as high as 50\% to 60\%. ${ }^{4}$ To help identify patients who have adrenal insufficiency during times of sepsis or septic shock, an adrenocorticotropic hormone (ACTH) stimulation test can be performed. ${ }^{3}$ If adrenal insufficiency is confirmed (as evidenced by a lack of response to ACTH stimulation), exogenous corticosteroids may be administered to improve the hemodynamic response. ${ }^{3}$

In a recently completed trial, the Corticosteroid Therapy of Septic Shock (CORTICUS) study, hydrocortisone supplementation had no mortality benefit for patients with septic shock, ${ }^{5}$ even though literature published before the CORTICUS trial had suggested a mortality benefit if exogenous corticosteroids were administered to patients with septic shock accompanied by adrenal insufficiency. In particular, the recommendation to administer exogenous corticosteroids stemmed from a trial of patients with septic shock who remained hypotensive despite receiving fluid and inotrope therapy for $1 \mathrm{~h}^{6}{ }^{6}$ The patients underwent the ACTH stimulation test, and those with no response were given hydrocortisone and fludrocortisone; shortterm and long-term mortality rates were significantly reduced in these patients. However, in the larger, more recent multicentre CORTICUS trial, hydrocortisone supplementation did not improve survival for patients with septic shock. ${ }^{5}$ More specifically, there was no difference in mortality at 28 days and 1 year between patients who received hydrocortisone and those who received placebo, whether or not they had had a response to the ACTH stimulation test.

Given this new evidence of a lack of mortality benefit with ACTH stimulation testing and hydrocortisone supplementation among patients with septic shock, it appears that the ACTH stimulation test should not be performed in these patients. Nonetheless, the ACTH stimulation test may still prove useful for certain patients. For example, this test may help to rule out Addison disease, confirm whether previous exposure to systemic corticosteroids has caused suppression of the hypothalamicpituitary-adrenal (HPA) axis, and rule out various causes of metabolic disturbances such as unexplained hyponatremia. Therefore, this study was undertaken to determine the frequency of appropriate and inappropriate use of the ACTH stimulation test for patients in the intensive care unit (ICU) at a tertiary care hospital with more than 500 beds in Vancouver, British Columbia.

\section{METHODS}

Approval was obtained from the University of British Columbia Clinical Research Ethics Board before initiation of the study. This project was conducted in partial fulfillment of the requirements for completion of a hospital pharmacy residency year by the first author (O.S.).

\section{Study Population}

All patients who underwent an ACTH stimulation test while in the 19-bed ICU between January 1 and December 31, 2007, were included. Eligible patients were identified by crossreferencing the hospital's database of ICU admissions against the hospital pharmacy's database of patients who had received ACTH during the specified time period.

\section{Data Collection}

The electronic health records of all eligible patients were reviewed to determine the indication for which the ACTH stimulation test had been ordered. The indication was classified as either appropriate or inappropriate, according to the following a priori definitions.

The following indications were defined as appropriate:

- symptoms or signs of Addison disease

- masked adrenal insufficiency

- suspicion of glucocorticoid-induced suppression of the HPA axis

- diffuse dysfunction of the hypothalamus or pituitary gland

- unexplained shock in the absence of sepsis, hypovolemia, or cardiac dysfunction

Inappropriate indications were any indications not included in the list of appropriate indications, above, including the following situations:

- patient had received etidomate (a known suppressor of the adrenal glands) within previous $48 \mathrm{~h}$

- patient had septic shock unresponsive to fluid management and inotropes

- patient had no record of systemic corticosteroid use within the previous 3 months

The indication for the ACTH stimulation test was determined from the following sources:

- written rationale documented by the physician in the interdisciplinary progress notes of the electronic health record and/or

- the patient's clinical picture over a period of several days before the ACTH stimulation test, based on a review of chart notes and the critical care flow sheet:

- Addison disease: unexplained hyperkalemia, unexplained generalized skin pigmentation, unexplained fatigue, with or without unexplained eosinophilia

- septic shock unresponsive to fluid management and inotropes: defined by central venous pressure $>10 \mathrm{~mm} \mathrm{Hg}$ and concurrent IV infusion of norepinephrine for $1 \mathrm{~h}$ or more 
- masked adrenal insufficiency: defined by requirement for re-institution of corticosteroids 1 to 2 days after their discontinuation to maintain hemodynamic stability

In addition, each patient's medication administration record during the admission was reviewed to determine whether the patient had been exposed to any of the following:

- etomidate (known to cause transient suppression of the adrenal glands for $24 \mathrm{~h}$ after single dose)

- systemic corticosteroids, in which case suppression of the HPA axis was assumed if the patient had received systemic corticosteroids for 3 weeks or longer within the 3 months before ACTH stimulation at the following doses or equivalent:

- hydrocortisone $>30 \mathrm{mg} /$ day

- prednisone $>7.5 \mathrm{mg} /$ day

- dexamethasone $>0.75 \mathrm{mg} /$ day

\section{RESULTS}

There were 586 admissions to the ICU during the study period. A total of $35 \mathrm{ACTH}$ stimulation tests had been performed for 32 patients, with 2 patients receiving the test more than once. Of the 35 tests performed, only 8 (23\%) were classified as having an appropriate indication (Table 1); the remaining 27 (77\%) were classified as having an inappropriate indication (Table 2).

During the course of data collection, 2 new appropriate indications and 3 new inappropriate indications were identified. Unexplained hypoglycemia and unexplained hyponatremia were added to the list of appropriate indications. The newly added inappropriate indications were fluctuating hypotension, infection in the absence of shock, and no documented or clinically apparent reason.

Over the period from January to September 2007, the number of ACTH stimulation tests ordered for patients with septic shock unresponsive to fluid and inotrope management declined (Figure 1). During November and December 2007, there were no orders for the ACTH stimulation test at all.

\section{DISCUSSION}

Overall, during the year 2007, the ACTH stimulation test was ordered for an inappropriate indication more often than for

Table 1. Appropriate Indications for Adrenocorticotropic Hormone Stimulation Test

\begin{tabular}{lc} 
Indication & No. of Orders \\
\hline Unexplained shock in absence of sepsis, & \\
hypovolemia, or cardiac dysfunction & 3 \\
Masked adrenal insufficiency & 1 \\
Diffuse hypothalamic-pituitary dysfunction & 1 \\
Addison disease & 1 \\
Unexplained hypoglycemia & 1 \\
Unexplained hyponatremia & 1 \\
Total & 8 \\
\hline
\end{tabular}

an appropriate indication (27 times versus 8 times, respectively). The majority of tests with an inappropriate indication were for septic shock unresponsive to fluid and inotropes (15/27). This result was expected, as most of the literature before the CORTICUS study suggested that patients with septic shock and no response to the ACTH stimulation test experienced a mortality benefit from exogenous administration of corticosteroids. ${ }^{6}$ However, the recent CORTICUS trial demonstrated a lack of benefit of the ACTH stimulation test for these patients. ${ }^{5}$ The results of the CORTICUS trial were initially made public through an abstract presentation during the 19th Congress of the European Society of Intensive Care Medicine in Barcelona, Spain, on September 27, 2006, and the full article was published in January 2008..$^{5}$ Increasing awareness of the CORTICUS results as the year progressed might explain the results presented here, which revealed declining use of the ACTH stimulation test for this patient population.

The number of ACTH stimulation tests ordered inappropriately for suspicion of glucocorticoid-induced suppression of the HPA axis (6/27) was surprising. In all of these cases, the patient had been using systemic corticosteroids for less than 3 weeks, sometimes for only a few days. This suggests that physicians may be underestimating the duration of systemic glucocorticoid therapy needed to cause HPA-axis suppression; alternatively, there may be a lack of consensus about the required duration of such therapy.

This study has also highlighted a potential point of intervention for ICU clinical pharmacists. Given the variety of inappropriate indications for the ACTH stimulation test reported here, it should be possible for the clinical pharmacist to provide screening at the bedside whenever this test is ordered. This would help to ensure that the test is used only for truly appropriate indications; the clinical pharmacist would be responsible for permitting the test to be performed. In cases with an inappropriate indication, the clinical pharmacist could discuss a more appropriate course of action with the prescriber.

The limitations of this study included its retrospective design and its reliance on a review of health care records for data collection, which necessitated some assumptions in classifying

Table 2. Inappropriate Indications for Adrenocorticotropic Hormone Stimulation Test

\begin{tabular}{lc} 
Indication & No. of Orders \\
\hline Septic shock unresponsive to fluid and inotropes & 15 \\
Use of systemic glucocorticoid for $<3$ weeks & 6 \\
No documented or clinically apparent reason & 4 \\
Investigation of fluctuating hypotension & 1 \\
Infection in the absence of shock & 1 \\
Total & 27 \\
\hline
\end{tabular}




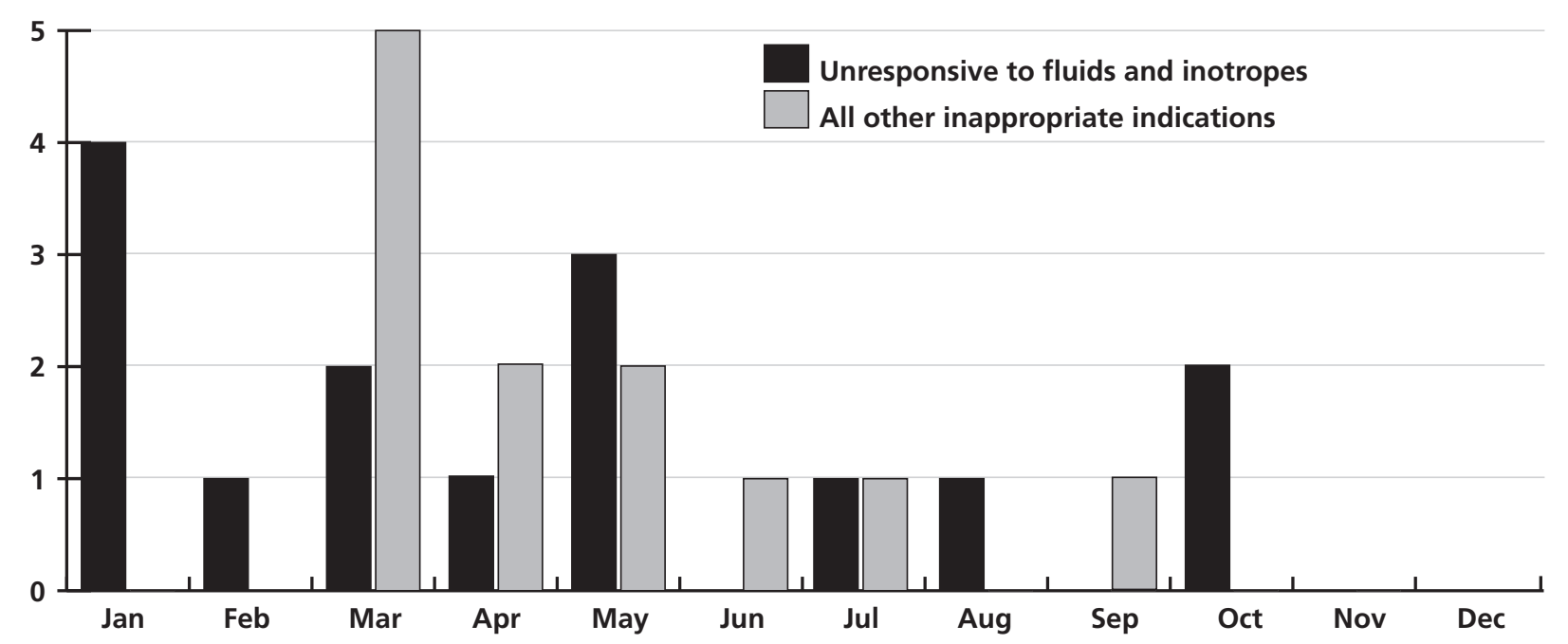

Figure 1. Monthly orders for adrenocorticotropic hormone stimulation test for patients with septic shock unresponsive to fluid and inotropes and for other inappropriate indications in the year 2007.

the data. For example, we defined adequate fluid resuscitation in patients with shock as central venous pressure above $10 \mathrm{~mm} \mathrm{Hg}$. Although central venous pressure is often used as a measure of fluid balance, it can be unreliable because elevation of this pressure may also be caused by regurgitation or stenosis at the tricuspid valve, right ventricular failure, constrictive pericarditis, or pulmonary embolism. ${ }^{7.8}$ Moreover, some critically ill patients who are undergoing mechanical ventilation require higher settings for positive end-expiratory pressure, which can decrease cardiac output, thereby contributing to shock, despite an elevated central venous pressure reading. ' We did not take these factors into account in our review of the health care records. Even if we had tried to account for these confounders, there are no established thresholds at which their influence should be excluded. It is also reasonable to assume that the number of patients with these confounders was relatively small, and their exclusion would not have significantly affected the results reported here.

Given the high rate of inappropriate use of the ACTH stimulation test (77\%), it appears that clarification of the overall role of this test is needed in the ICU at this tertiary care hospital. More than half of the inappropriate orders $(56 \%)$ were for patients with continuing septic shock, despite fluid and inotrope therapy. In addition, these results depict a change in prescribing trends over time, which may reflect adoption of the latest evidence from the CORTICUS trial. In addition, clarification of the conditions required to produce glucocorticoid-induced suppression of the HPA axis may be warranted to help prevent further unnecessary use of the ACTH stimulation test in cases where this problem is unlikely.

\section{References}

1. Prigent $\mathrm{H}$, Maxime V, Annane D. Clinical review: corticotherapy in sepsis. Crit Care 2004;8(2):122-129.
2. Marx C. The systemic adrenal stress response in severe sepsis and critical illness. Clin Intensive Care 2005;16(2):57-64.

3. Gonzalez H, Nardi O, Annane D. Relative adrenal failure in the ICU: an identifiable problem requiring treatment. Crit Care Clin 2006; 22(1):105-118.

4. Marik PE, Zaloga GP. Adrenal insufficiency in the critically ill. Chest 2002;122(5):1784-1796.

5. Sprung CL, Djillali A, Keh D, Moreno R, Singer M, Freivogel K, et al. Hydrocortisone therapy for patients with septic shock. $N$ Engl J Med 2008;358(2):111-124.

6. Djillali A, Sebille V, Charpentier C, Bollaert PE, Francois B, Korach JM, et al. Effect of treatment with low doses of hydrocortisone and fludrocortisone on mortality in patients with septic shock. JAMA 2002;288(7): 862-871.

7. Broeseker A. Monitoring in the critically ill. U S Pharm 1995 Nov;: H14-44. Publisher: Jobson Publishing.

8. Norris DL, Klein LA. What all those pressure readings mean...and why. $R N 1981$ Oct::35-41. Publisher: Advanstar Communications.

9. Cawley MJ. Mechanical ventilation:a tutorial for pharmacists. Pharmacotherapy 2002;27(2):250-266.

Osric Sin, BSc(Pharm), was, at the time of this study, completing a Hospital Pharmacy Residency with Vancouver Coastal HealthProvidence Healthcare, Vancouver, British Columbia. He is now with St Paul's Hospital.

Glen Brown, BSC(Pharm), PharmD, FCSHP, BCPS, is with the Pharmacy Department, St Paul's Hospital, Vancouver, British Columbia.

Greg Grant, MD, is with St Paul's Hospital, Vancouver, British Columbia.

Address correspondence to:

Osric Sin

Pharmacy Department

St Paul's Hospital

1081 Burrard Steet

Vancouver BC V6Z 1 Y 6

e-mail: osric.sin@vch.ca 